\title{
TECTONIC PROCESSES MODELING FOR HIGH-LEVEL RADIOACTIVE WASTE DISPOSAL
}

\author{
Vladislav Morozov ${ }^{1}$, Victor Tatarinov ${ }^{1,2}$, Ilya Kolesnikov ${ }^{1}$, \\ Alexander Kagan ${ }^{1}$, Tatiana Tatarinova ${ }^{2}$ \\ 1- Geophysical Center of Russian Academy of Sciences \\ 3 Molodezhnaya str, Moscow, 117296, Russia \\ E-mail: v.tatarinov@gcras.ru \\ 2- The Schmidt Institute of Physics of the Earth (IPE) \\ 10 B.Gruzinskaja str., bul. 1., Moscow, 123995, Russia
}

\begin{abstract}
The possibility of using deep geological formations to dispose of high-level radioactive waste $(H L W)$ is a subject raising heated debate among scientists. In Russia, the idea of constructing HLW repository in the Niznekansky granitoid massif (NKM) in Krasnoyarsk area is widely discussed. To solve this problem we are elaborating a technology associated with time - space stability prediction of the geological environment, which is subject to geodynamic processes evolutionary effects. It is based on the prediction of isolation properties stability in a structural tectonic block of the Earth's crust for a given time. The danger is in the possibility that the selected structural block may be broken by new tectonic faults or movements on a passive fault may be activated and thus underground water may penetrate to HLW containers.
\end{abstract}

Keywords: tectonic, radioactive waste, evolution of Earth's crust, stress, faults, GPS.

\section{Introduction}

Scientists have heated discussions on the possibility of using deep geological formations to dispose of high-level radioactive waste (HLRW). In Russia the possibility of construction a HLRW repository in the NKM in the area of city Krasnoyarsk is being widely debated [1]. The major problem is the required prognosis of the geological environment isolation characteristics persistence for a long interval of time such as $10^{4}-10^{5}$ years. In such a period of time, geodynamic processes are able to make radical changes in engineering geology and hydrogeology features (variation of groundwater level, water-bearing horizon head, new infiltration channels formation and others) and result in the destruction of HLRW repository with disastrous impacts on the environment. Solving this problem, we are developing a technology to predict the stability in time and space of the geological environment, which is subject to evolutionary effects of geodynamic processes [2-3]. It is based on the use of a combination of methods having the final goal to make a prognosis of structural tectonics blocks destruction of the Earth's crust.

Any area of the Earth's crust in which a repository could be planned to be located is a system of blocks limited with surfaces of tectonic dislocations of various hierarchy levels. The technique of selecting sites suitable for HLRW repositories construction is based on the search in stable geological areas for structural tectonic blocks having the least density of faults in maximum volume. At the same time, evidently, there are no areas free of dislocations in the crust and the separated blocks are relatively less dislocated; local stress fields, which are non-stationary with time, surround them. The blocks get destroyed, and new channels of ground water infiltration are formed.

\section{Materials and methods}

The elaboration of prognosis technology (fig. 1) is based on the following prerequisites:

1. The evolution of the Earth's crust is determined by the intensity of tectonic process development in the region. The process velocity depends on the level of effective tectonic stresses and physical and mechanical characteristics of rocks. 
2. Tectonic stresses field retaining the inherited tendencies of the region tectonic evolution varies in time and space.

3. Modern stress - strain state in combination with the inherited tendency of time - space variation of tectonic stress local fields is a basis of the destruction processes development in structural tectonic blocks.

4. Inherited directions depending on the effective tectonic stress tensor determine the direction of new tectonic faults formation and the old faults activation.

5. Local areas of increased stress concentration are the most likely places to initiate destruction of the geological environment and the structural block.

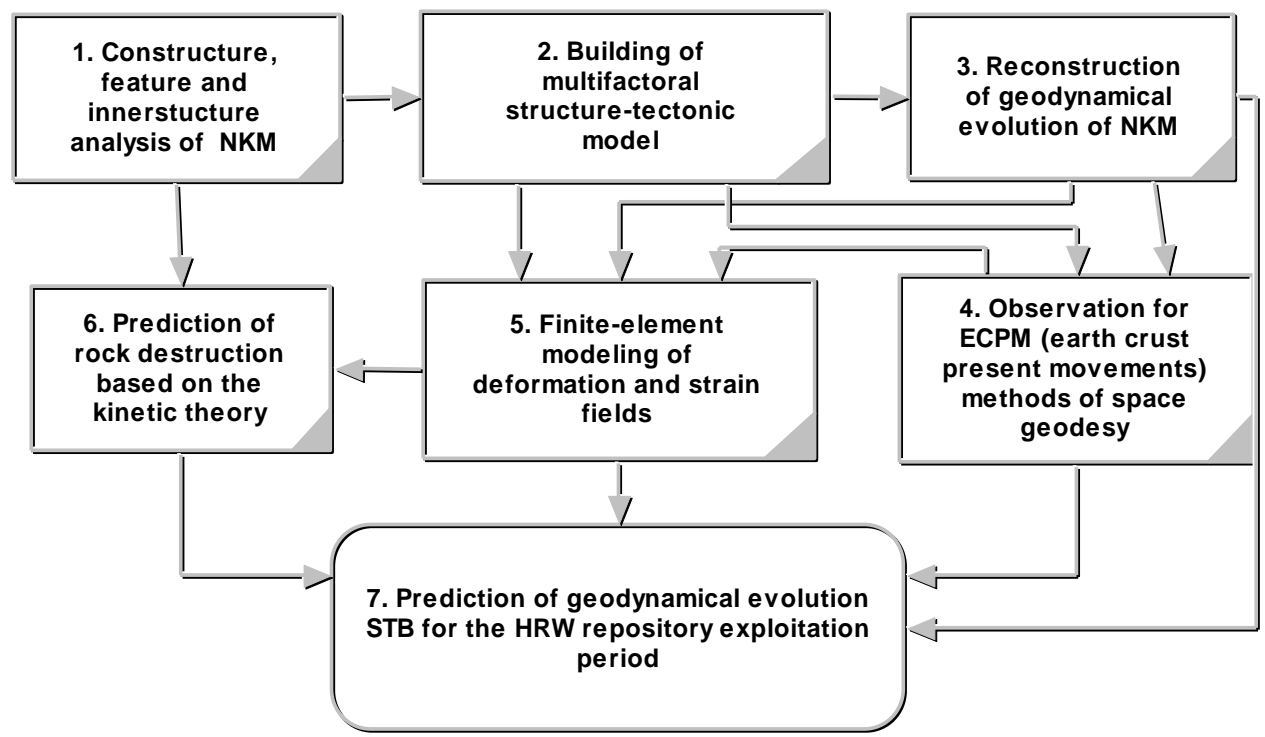

Fig.1. The basic stages of technology

From practical viewpoint, it is reasonable to predict crustal blocks evolution of NKM in Russia where work is being carried out to select a site of underground laboratory construction. The urgency of work in that region is caused by the fact that now a decision is to be made on the underground laboratory construction (this stage is obligatory in compliance with the concept of HLRW repositories construction). Thus the prediction of geological environment evolution will allow us to avoid unjustified financial loss and to decrease the risk of radionuclide pollution of the environment if the selected sites do not meet safety standards.

\section{Results}

Multifactoral structure-tectonic model of NKM. NKM is a single, independently formed and synorogenic bathylite (fig. 2).

Top edge morphology. Massive top edge morphology analysis is important because the surface of top edge is its depth geodynamical activity «mirror». NKM occupies a floor space of $2000 \mathrm{sq}$. km. Its length amount to $60 \mathrm{~km}$. in the north-west direction and its width amount to $23-35 \mathrm{~km}$. Top edge densely desiccated with present erosion processes. Vary of absolute elevation is amount $250 \mathrm{~m}$ with a maximum elevation more than $500 \mathrm{~m}$.

Relief flattering action, which was added by present elevation average thickness diminution from of loose deposits in amount of $50 \mathrm{~m}$, was applied for the revealing of general regularity for NKM top edge structure. Scheme on fig. 3 is a result of this transformation. Its analysis shows that east roof half is raised and has enough simple rolling relief with smooth isolines and minimum number of areas with harsh grade of isolines massif roof. 


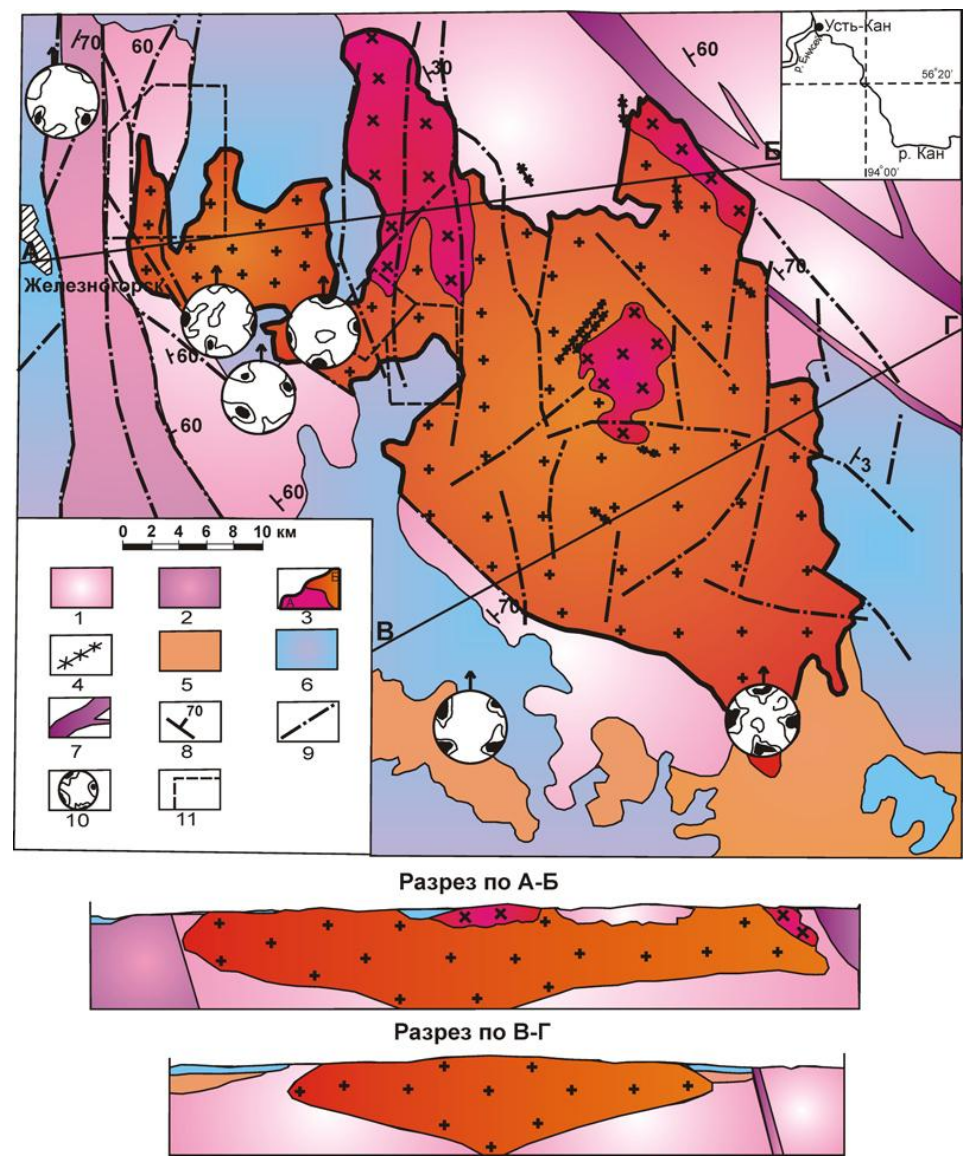

Fig.2. NKM area geological structure scheme

1- geiss (AR); 2- amphibolite, quartzite and marble (AR-PR); 3- contour of NKM granitiods: a-diorite of 1-st stage; b- granite of 2-nd stage; 4- dikes; 5- terrigenous-volcanic deposits $\left(\mathrm{PZ}_{2}\right)$; 6-terrigenous deposits (J); 7- mylonite areas; 8- main faults; 9- grike orientation diagram; 10- rock position elements; 11- areas of detailed research (from south-east to north-west: "Kamenniy", "Itatskiy", "Eniseiskiy")

The Tectonic features of Relief. Relief is a second element of NKM structure-tectonic model, cause it describes its present tectonic activity. Relief density dissection scheme is the integral characteristic of activity. This scheme built in $C_{I R}$ isolines (fig. 4). This coefficient was estimated by clusters with $4 \times 4 \mathrm{~km}$. sliding window, like a dependence of difference between minimum and maximum absolute elevation to unit area. $C_{I R}$ reflects type of vertical ECPM and present endogen area activity. Level of $C_{I R}$ rises when rate elevation becomes density.

Right side of NKM, situated to the east from Maliy Itat river, defines by more density elevation $\left(C_{I R} \approx 200 \div 400\right)$. Area with maximum values of $C_{I R}$ situated on the territory with maximum roof elevation. In this area Kan river changes its course direction from meridional to latitudional and valley becomes deeply incised into massif. Just at that place occurs maximum thickness of granites. Another part, situated to the west from M. Itat river, defines by low $C_{I R}$ amount $(\approx 150 \div 100)$ and that gives an tectonic stability evidence of this area. 


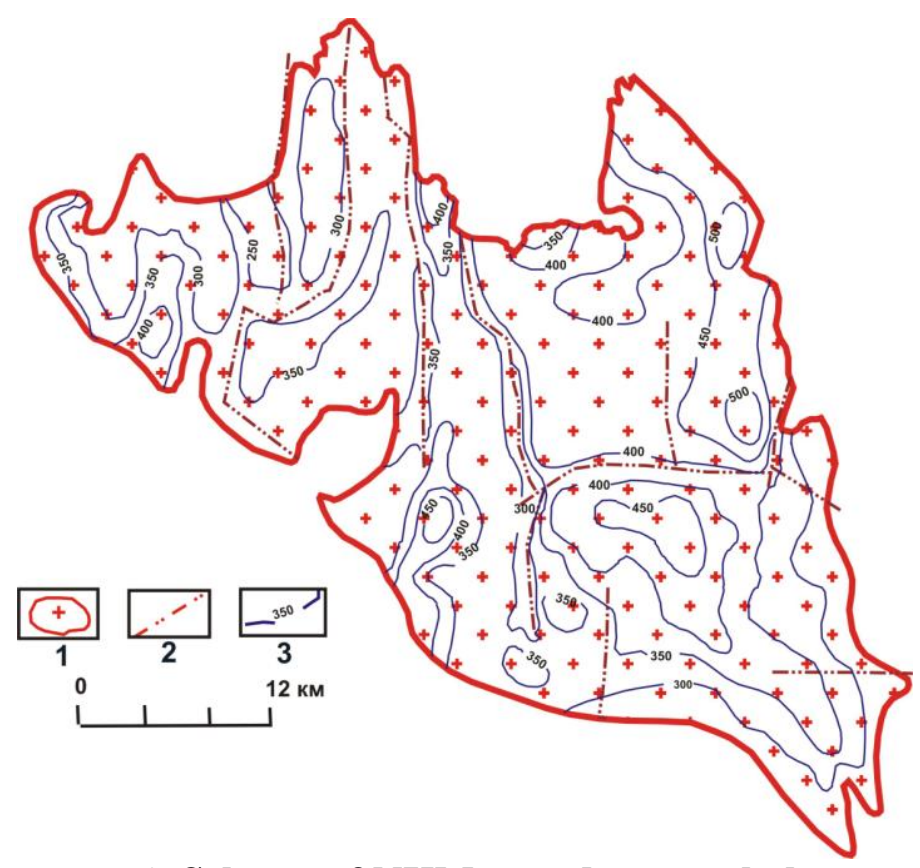

Fig.3. Scheme of NKM top edge morphology

1- NKM contour; 2- main faults; 3 - contour lines of NKM top edge

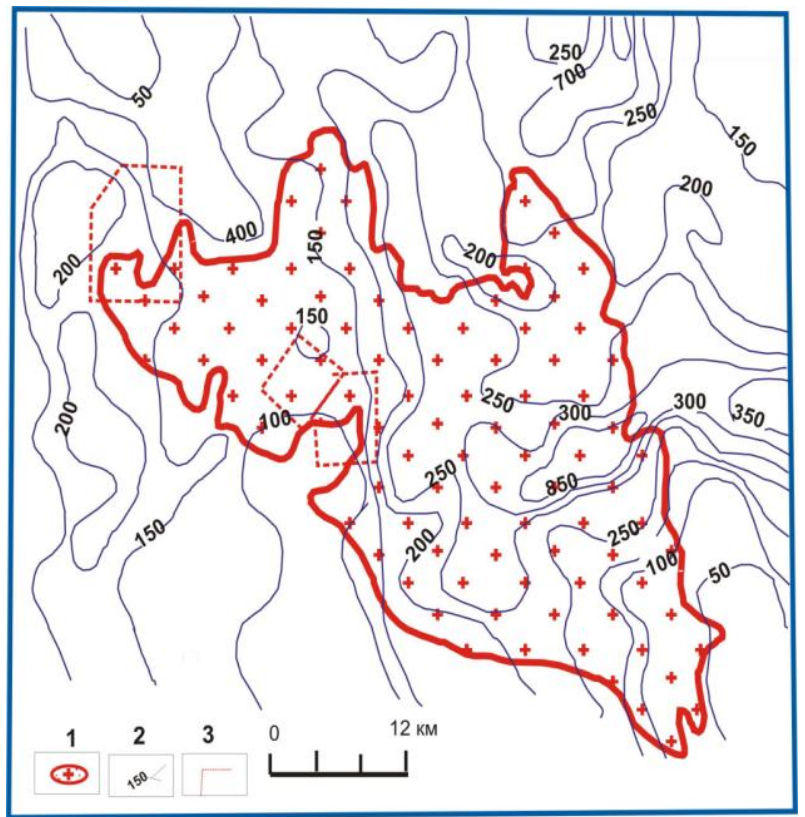

Fig.4. Relief desiccate density map

1- granites, 2- isolines of $\mathrm{C}_{\mathrm{IR}}$; 3- "Kamenniy", "Itatskiy", "Eniseiskiy" areas contours

"Eniseiskiy" block situated in rather unsafe area, which one contacts in the west to the maximum $C_{I R}$ level area. Blocks "Kamenniy", "Itatskiy" situated within the stable part of NKM. This part of NKM slowly rises on the present stage of region tectonic evolution.

Analysis of block morphostructures and cleavage. Morphostructural relief analysis of 1:200 000 scale enabled creating detailed block composition of the area. This included revealing relief faults and blocks of varied height (fig. 5) into ten block levels with $50 \mathrm{~m}$ hypsometric gaps and 580 to $230 \mathrm{~m}$ height range. They are mainly isometric 2 to $8 \mathrm{~km}$ in diameter with often intra-block faults that could not be referred to as inter-block due to different height of their sides. The Eastern part of NKM features higher hypsometric level with blocks absolute height of 530 to $380 \mathrm{~m}$. The Western part has lower blocks ranging 430 to $280 \mathrm{~m}$. 


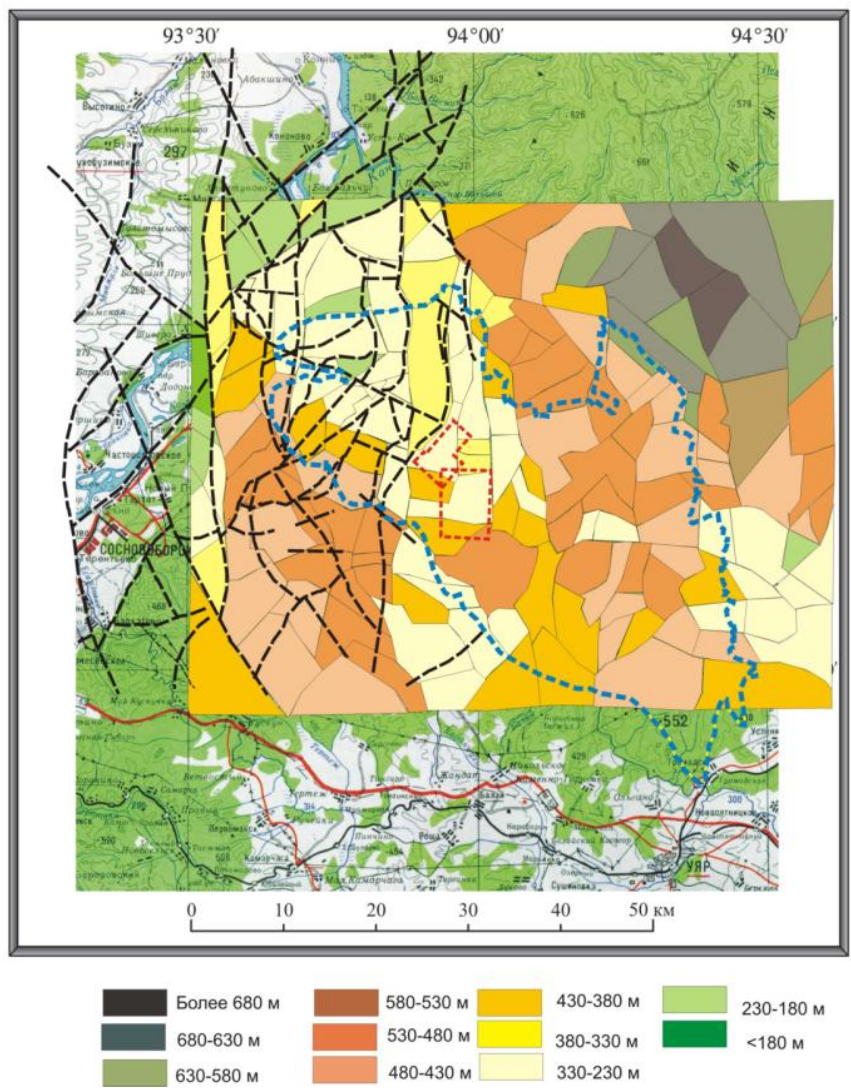

Fig.5. Structural and tectonic blocks of NKM

Finding structural non-uniformities and sign of tectonic activity. The described NKM model can be substantially improved and adjusted based on the survey of geophysical field, which enable identifying and tracing deep-earth geodynamic zones. In these terms, the data of airborne magnetic survey shall be processed through Euler inverse filtering with RODIN and KRISTALL artificial intelligence algorithms. See details in [4].

Fig. 6 displays interpretation of anomaly magnetic field for $n=3,0$ and pattern 15 (center of mass for anomaly-forming objects). Application of cluster analysis enabled identifying isometric structure blocks dominating the NKM structure with average size of 6 to $9 \mathrm{~km}$. Linear zones of different height found could be large tectonic faults.

Simulating stress-deformed state. The aforementioned results of structural-tectonic and cluster analysis were used as the basis for SDS simulation through isoparametric rectangular finite elements of the finite elements method. Reconstructing the tectonic conditions of the area directed and measured the main stress activities (NE - SW).

Distributing the stress fields identified the following specificities:

1. Linear zones that can be geodynamic zones of faults through elongated zones of increased $\sigma_{l}$ and $\tau_{x y}$ values, with dominating orientation $45^{\circ}$ to the main stress direction.

2. The fault system of the central part of the area generally contributes to unloading a rock mass with average stress field of 10 to 25 megapascal. 


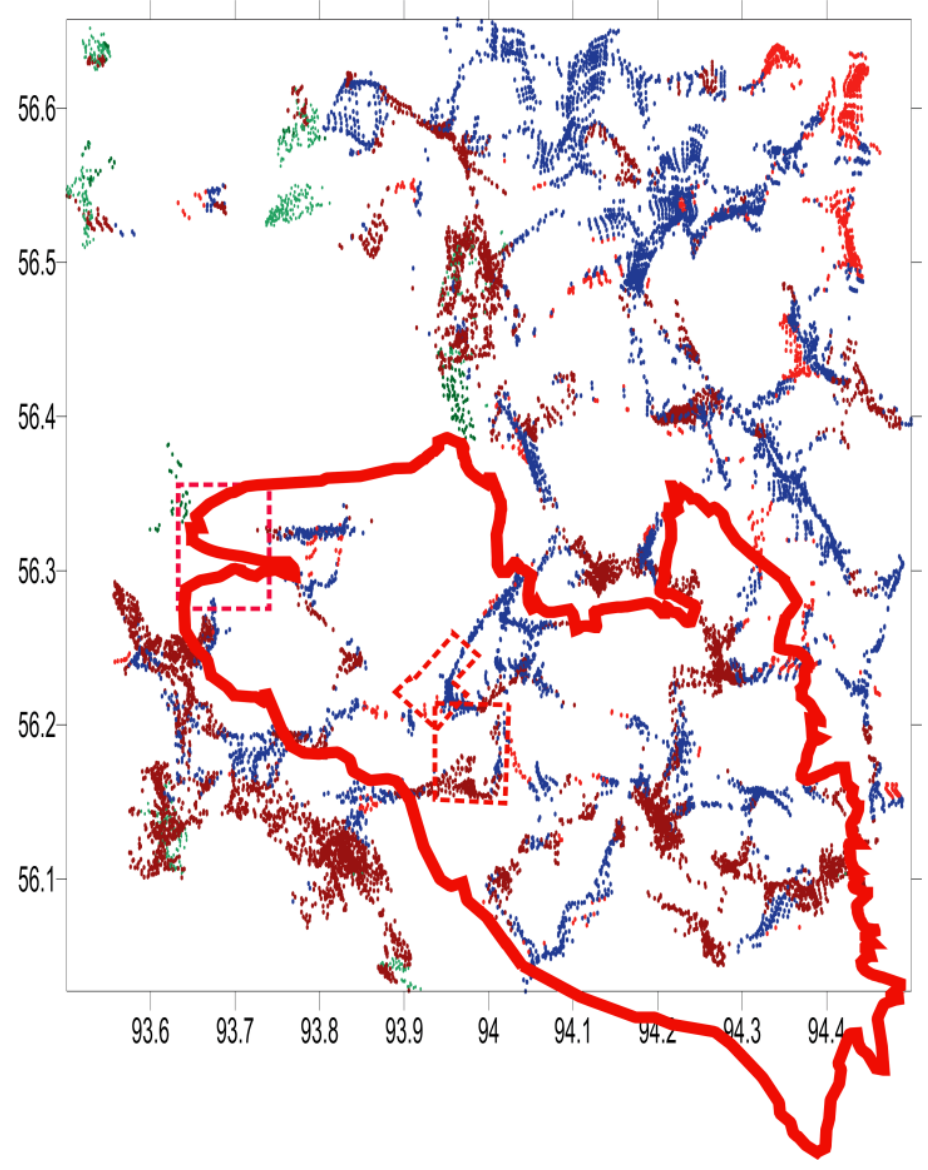

Fig. 6. Interpretation of anomaly magnetic field

Monitoring the modern earth crust movements with GPS. Monitoring of the modern earth crust movements is a crucial step when forecasting how safe the isolation features of geologic formations will be. No geodynamic mode can be researched without definition of the rate the main tectonic deformations within the area of 100-200 km radius have. Analyzing the entire database, including space-geological images, geological and geophysical data, different tectonic maps and real topography of the area enabled identification of GPS/GLONASS points and optimizing the geodynamic network (fig. 8).

The main problem was selecting the place meeting the following criteria for survey:

1. No forest and radio wave deflector within $15 \mathrm{~m}$ from each mark.

2. Exposure of bedding rocks or a building with secure basement.

3. Transportation availability of the survey site.

Meeting all the requirements above was not feasible for the NKM area, because almost no exposures found. This is why uneven configuration of the network is intended to optimization and density increasing. Survey is planned to be carried out twice a year in a 5-6 year term. 


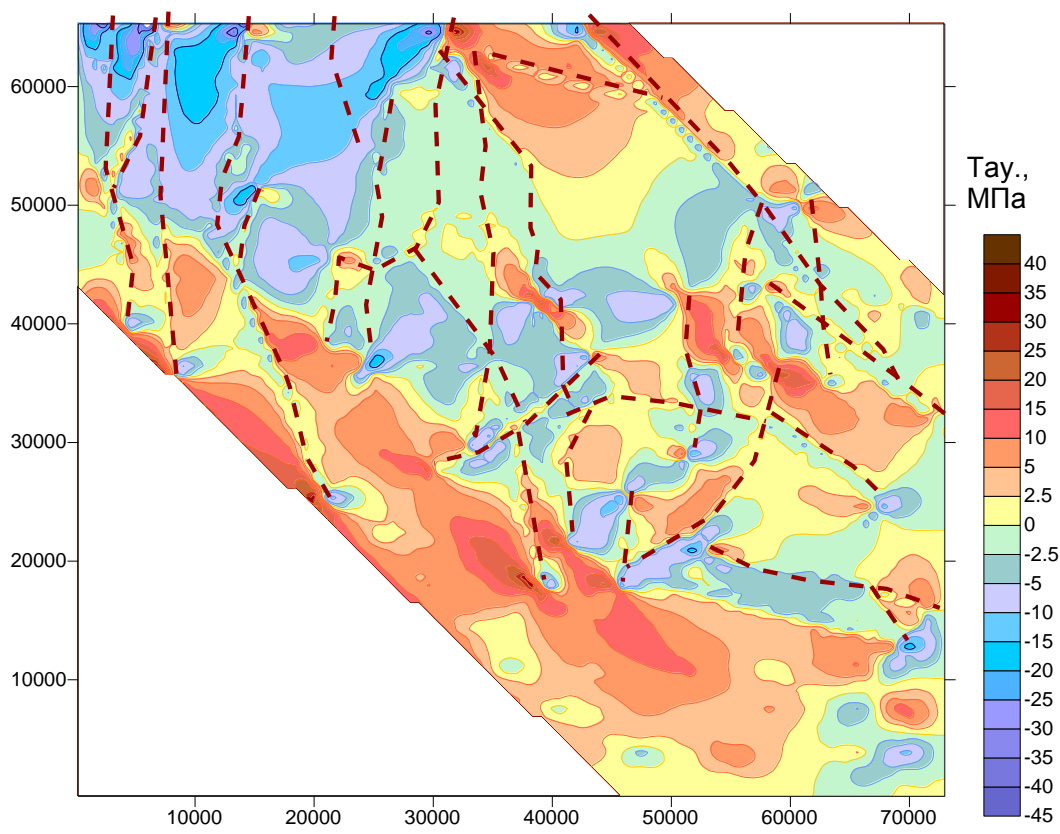

Fig. 7. SDS simulation, $\tau_{x y}$ component

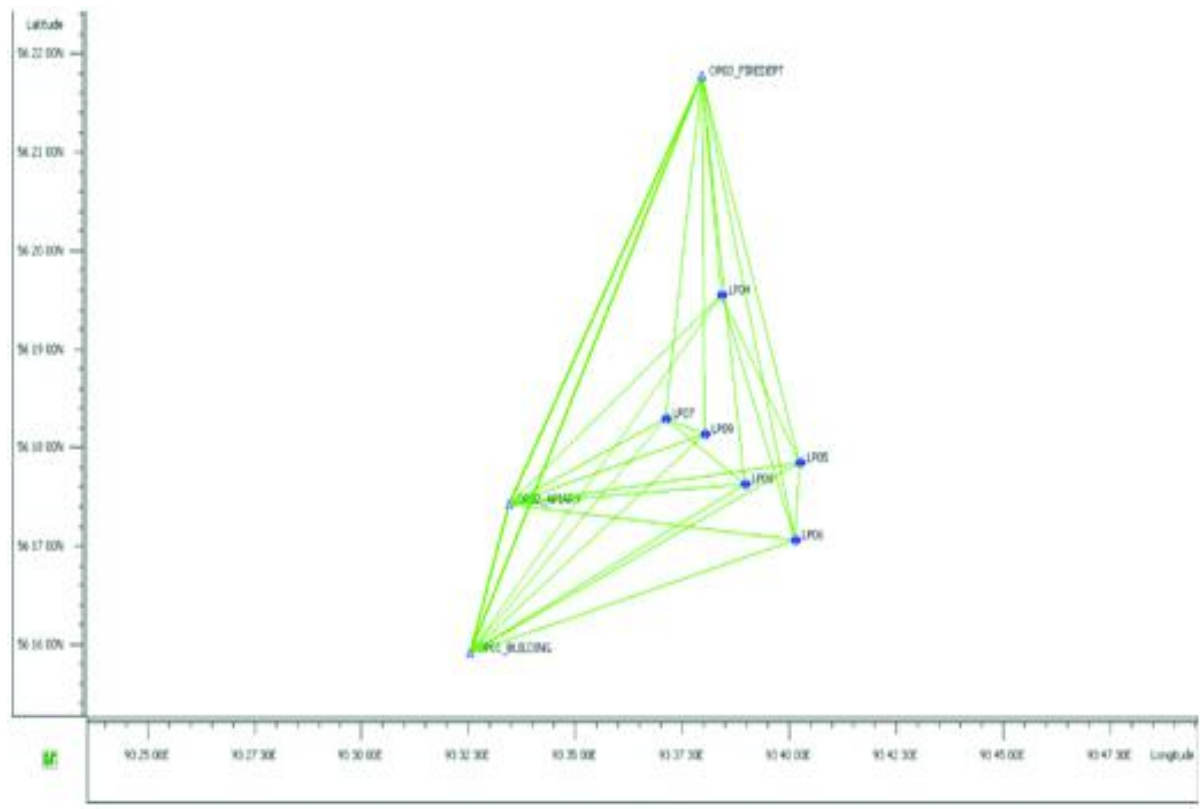

Fig. 8. GPS point location in

\section{References}

1. Anderson E. B., Alekseev E. P., Datsenko V. M. et al. The results of combined geological and geophysical and specialized research in the area of Kamenny and abutting areas (Nizhnekansky massif). Report on research work of GUP NPO V. Khlopin Radium Institute. S-Petersburg, 2001 (in Russian).

2. Morozov V. N., Tatarinov V. N. The methods of selecting crustal areas of the Earth to dispose of ecologically hazardous waste. Geoecology. M. 1996. No. 6. Pp. 109 - 120 (in Russian).

3. Morozov V. N., Tatarinov V. N. Tectonic processes development with time in the areas of HLW disposal from expert assessment to prognosis. Int. Nuclear Energy science and Technology, Vol. 2 . No, 1/2. 2006. Pp. 65-74.

4. Mikhailov V., A. Galdeano, M. Diament, A. Gvishiani and etc. Application of artificial intelligence for Euler solutions clustering. Geophysics. 2003, vol. 68, no. 1, p.168-180 (in Russian). 